\title{
Effect of COVID-19 Pandemic on Physical Activity Habits, Musculoskeletal Pain, and Mood of Healthcare Workers
}

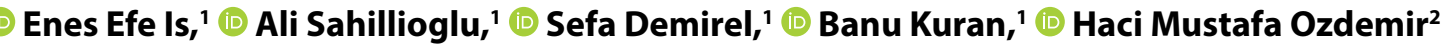 \\ 'Department of Physical Medicine and Rehabilitation, University of Health Sciences Turkey, Sisli Hamidiye Etfal Teaching and Research \\ Hospital, Istanbul Turkey \\ ${ }^{2}$ Department of Orthopedics and Traumatology, University of Health Sciences Turkey, Sisli Hamidiye Etfal Teaching and Research \\ Hospital, Istanbul Turkey
}

\begin{abstract}
Objectives: Self-isolation seems to be the best way to slow down the coronavirus disease 2019 (COVID-19) outbreak, but it may also have negative impact on physical and mental health. The aim of this study was to investigate the changes in physical activity habits during the outbreak and also the impact of the pandemic on musculoskeletal pain and mood in correlation with physical activity in healthcare workers.

Methods: This study is conducted through Google Forms web survey platform. A total of 310 hospital staffs completed the Google Forms questionnaire in 2 weeks during lockdown and curfew period in Istanbul. The questionnaire included 60 questions including demographic, occupational, COVID-19 exposure data, physical activity habits, musculoskeletal pain, and mood.

Results: There was a significant difference between physical activity habits before and after the pandemic $(p<0.001)$. Individuals engaged in regular physical activity (regardless of duration) had significantly higher happiness ratings ( $p=0.002$ ). No statistically significant difference was found between the duration of physical activity and the musculoskeletal pain during the pandemic.

Conclusion: Pandemic caused a decrease in physical activity, an unhappy and anxious mood, and an increase in musculoskeletal pain of healthcare workers. Participants who were doing regular physical activity were less unhappy, but no relationship between exercise and musculoskeletal pain was found which might be related to psychosocial state of the participants who worked under great stress with high effort during the pandemic.

Keywords: COVID-19; healthcare worker; mood; musculoskeletal pain; physical activity.

Please cite this article as "Is EE, Sahillioglu A, Demirel S, Kuran B, Ozdemir HM. Effect of COVID-19 Pandemic on Physical Activity Habits, Musculoskeletal Pain, and Mood of Healthcare Workers. Med Bull Sisli Etfal Hosp 2021;55(4):462-468".
\end{abstract}

$S_{2}$ nce the identification of the first case in December 2019 in Wuhan (Hubei, China), the coronavirus disease 2019 (COVID-19) has spread rapidly throughout the world and resulted in an ongoing pandemic. Turkey, with the first confirmed case on March 11,2020, is also seriously affected by the outbreak like the rest of the world..$^{[1]}$ Many countries, among them Turkey, took prompt and radical public health measures to slow down the contagion, especially in the beginning phase including curfews, travel restrictions, and calls for self-isolation which profoundly changed our lives in many ways. More than 4 billion people around the world were called on compulsory or recommended to remain at

Address for correspondence: Enes Efe Is, MD. Saglik Bilimleri Universitesi, Sisli Hamidiye Etfal Egitim ve Arastirma Hastanesi,

Fiziksel Tip ve Rehabilitasyon Anabilim Dali, Istanbul, Turkey

Phone: +90 2123735000 E-mail: enefeis@gmail.com

Submitted Date: March 04, 2021 Accepted Date: April 22, 2021 Available Online Date: December 29, 2021

${ }^{\circ}$ Copyright 2021 by The Medical Bulletin of Sisli Etfal Hospital - Available online at www.sislietfaltip.org

OPEN ACCESS This is an open access article under the CC BY-NC license (http://creativecommons.org/licenses/by-nc/4.0/) 
home to fight the outbreak. ${ }^{[2]}$

Quarantine and self-isolation seem to be the best ways to slow down the outbreak, but it may also have negative impact on the isolated ones' physical and mental health status. COVID-19 threatened populations with several aspects regarding immobilization and lack of physical activity. At least 150 min of moderate-intensity physical activity (with bouts lasting $>10 \mathrm{~min}$ ) in a week is recommended for adults by the World Health Organization. ${ }^{[3]}$ The health benefits of physical activity and exercise include prevention of multiple diseases such as diabetes, cardiovascular diseases, osteoporosis, some cancer types, obesity both primarily and secondary, as well as preserving the cognitive and psychological wellness of the individual. ${ }^{[3-11]}$ Data from Hong Kong flu epidemic in 1997 show that regular exercisers had a lower mortality rate. ${ }^{[12]}$ Moderate-intensity exercise-induced immunomodulation might also have an important role to slow the progression of the disease. ${ }^{[13-15]}$

The aim of this study was to investigate the changes in physical activity habits during the outbreak of COVID-19 and the emotional impact of the pandemic in correlation with physical activity in healthcare workers who were under a big pressure because they had to fight the virus in the hospital and isolation at home.

\section{Methods}

This study is conducted through Google Forms web survey platform. The survey focused on the healthcare workers of Sisli Hamidiye Etfal Teaching and Research Hospital. Online survey was approved by the Clinical Trials Approval Office of the Ministry of Health and local hospital ethics committee (June 30, 2020/2861). It was distributed by the hospital administration and chief doctors of the departments. The participants were informed about the purpose of the research that it was approved by the ministry and the administration. They were also informed that participation was voluntary and his/her personal information would be confidential.

A total of 310 hospital staffs completed the Google Forms questionnaire in 2 weeks during lockdown and curfew period in Istanbul.

The questionnaire included 60 questions including demographic, occupational, COVID-19 exposure data, physical activity habits, musculoskeletal pain, and mood changes that were commonly experienced during disasters. Aerobic physical activity (with bouts lasting $>10 \mathrm{~min}$ ) duration before and during the pandemic was questioned as none, $<150 \mathrm{~min}$, or $>150 \mathrm{~min}$ each week. To reveal the effects of staying at home and the individual's preferences for physical activity more clearly, physical activity time while working in the hospital were not included in this duration. Change in physical activity habits in relation with the pandemic was also questioned. Musculoskeletal pain and its relation with physical activity status before and during the pandemic were assessed through a numeric scale $(0$ : No pain, 1: Pain did not increase, 2: Pain slightly, 3: Moderately, and 4: Extremely increased). Happiness was rated according to the respondent's perception in nine levels (1: Extremely, 2: Very, 3 Moderately, 4: Slightly unhappy, 5: Neutral, 6: Slightly, 7: Moderately, 8: Very, and 9: Extremely happy) and anxiety in five levels (1: Not anxious at all, 2: Slightly, 3: Moderately, 4:Very, and 5: Extremely anxious). In this article, individuals with a weekly physical activity duration of " 0 " min are called "non-exercisers" and individuals with duration of regular physical activity above this number were referred to as "regular exercisers."

\section{Statistical Analysis}

Statistical analysis was performed using SPSS v.21 (SPSS Inc., Chicago, IL, USA). Continuous data are presented as the mean \pm standard deviation and categorical data are presented as frequency and percentage. In the analysis of categorical variables, McNemar and marginal homogeneity tests were used for pre- and post-pandemic evaluations, and Chi-square and Fisher's exact tests were used where appropriate for other comparisons. In comparison of continuous variables, Mann-Whitney U-test was used for two groups and Kruskal-Wallis test was used for more than 2 groups. $\mathrm{P}<0.05$ was considered to be statistically significant.

\section{Results}

Table 1 shows characteristics of the participants. The study sample $(n=310)$ included 132 men (42.6\%) and 178 (57.4\%) women. About $61 \%(n=189)$ were $<39$ years old. About $41.9 \%(n=130)$ lived with his/her spouse and child(ren). Participants were $20.6 \%(n=63)$ residents, $19.6 \%(n=60)$ nurses, $17 \%(n=52)$ specialists, and $27.8 \%(n=36.6)$ were personnel (technicians, security, etc.). While $42.5 \%(n=132)$ were working in non-surgical departments, $25.5 \%(n=79)$ were working at surgical departments. About $34.2 \%(n=106)$ were working for more than 15 years while $35.2 \%(n=109)$ for $<5$ years.

About $35.5 \%(n=110)$ of the participants had more than 5 nightshifts during the pandemic. About 53.5\% ( $n=166)$ had a history of contact with a COVID-19 (+) patient. About $70.3 \%(n=218)$ were not tested for COVID-19. While $22 \%$ $(n=67)$ had chest computed tomography (CT) and $29.5 \%$ $(n=93)$ had swab sample performed, only $5.2 \%$ (16) of participants were diagnosed as COVID-19 (+). About $12.9 \%$ $(n=40)$ were quarantined for 14 days. 
Table 1. Demographic and occupational data of the participants

\begin{tabular}{|c|c|}
\hline Variable & n (\%) \\
\hline \multicolumn{2}{|l|}{ Sex } \\
\hline Male & $132(42.6)$ \\
\hline Female & $178(57.4)$ \\
\hline \multicolumn{2}{|l|}{ Age (year) } \\
\hline$<30$ & 109 (35.2) \\
\hline $30-39$ & $80(25.8)$ \\
\hline $40-49$ & $70(22.6)$ \\
\hline $50-59$ & $47(15.2)$ \\
\hline $60-69$ & $4(1.3)$ \\
\hline \multicolumn{2}{|l|}{ Who do you live with? } \\
\hline Alone & $57(18.4)$ \\
\hline Spouse/partner & $54(17.4)$ \\
\hline Spouse and child(ren) & $130(41.9)$ \\
\hline Parents & $29(9.4)$ \\
\hline Other & $40(12.9)$ \\
\hline \multicolumn{2}{|l|}{ Title } \\
\hline Staff & $58(19)$ \\
\hline Technician & $27(8.8)$ \\
\hline Nurse & 60 (19.6) \\
\hline Physiotherapist & $12(3.9)$ \\
\hline Resident & $63(20.6)$ \\
\hline Specialist & $52(17)$ \\
\hline Associate professor & $21(6.9)$ \\
\hline Professor & $13(4.2)$ \\
\hline \multicolumn{2}{|l|}{ Department } \\
\hline Internal medicine specialty & $132(42.5)$ \\
\hline Surgical specialty & $79(25.5)$ \\
\hline Laboratory & $31(10.0)$ \\
\hline Secretary & $30(9.7)$ \\
\hline Imaging & $25(8.1)$ \\
\hline Other & $13(4.2)$ \\
\hline \multicolumn{2}{|l|}{ Years in profession } \\
\hline$<5$ & 109 (35.2) \\
\hline $5-10$ & $50(16.1)$ \\
\hline $10-15$ & $45(14.5)$ \\
\hline$>15$ & $106(34.2)$ \\
\hline
\end{tabular}

Musculoskeletal pain frequency was compared among those participants who used to do regular physical activity for $<150 \mathrm{~min} /$ week and $>150 \mathrm{~min} /$ week or who did not engage in regular physical activity. With respect to musculoskeletal pain before COVID-19 quarantine, there was no significant difference between three groups. To understand whether there is a duration-based or independent relationship between pain and physical activity, further analyses were conducted. Regular exercisers $(<150 \mathrm{~min} /$ week $+>150 \mathrm{~min} /$ week) and non-exercisers and people who do physical activity $>150 \mathrm{~min} /$ week and who do physical activity $<150 \mathrm{~min} /$ week (non-exercisers are included in this group) were compared to investigate the effect of the cutoff value "150 min." No significant difference was found between these groups. And regardless of physical activity, 136 (66.0\%) out of 206 participants with musculoskeletal pain reported increased pain.

There was a significant difference between the physical activity habits of the participants before and after the pandemic ( $p<0.001)$. While $28.1 \%$ of those who did not engage in regular physical activity before the pandemic started to do physical activity $<150 \mathrm{~min} /$ week during the pandemic and $6.5 \%$ started to do physical activity more than $150 \mathrm{~min} /$ week. On the contrary, $37.8 \%$ of those who did physical activity more than 150 min a day before the pandemic quitted regular physical activity and became non-exercisers, while $38.7 \%$ started to do physical activity for $<150 \mathrm{~min} /$ week.

Comparing the physical activity habits of the participants before and after the pandemic in two groups (>150 min/ week vs. $<150 \mathrm{~min} /$ week + non-exercisers) with the McNemar test, we concluded that the physical activity habits of the participants had changed. We determined that $75.7 \%$ of the participants who did physical activity $>150 \mathrm{~min} /$ week previously ( $\mathrm{n}=111$ people) tend to do physical activity less during the pandemic. We found that $10.6 \%$ of those who did physical activity $<150 \mathrm{~min} /$ week before the pandemic started doing physical activity for more than 150 $\mathrm{min} /$ week. We commented that the participants started to do physical activity less than before during the pandemic, since a larger part of the participants started to do physical activity less. The aforementioned findings are summarized in Tables 2-4.

No statistically significant difference was found in terms of relationship between the duration of physical activity during the pandemic (during the home stay) and the musculoskeletal system pain during the home stay among groups.

Participants' physical activity status and its relationship with their happiness and anxiety parameters were also evaluated and compared. In this evaluation, both physical activity - happiness, physical activity - anxiety relationships (correlation), and the difference between groups (non-exercisers vs. $<150 \mathrm{~min} /$ week $+>150 \mathrm{~min} /$ week and non-exercisers vs. $<150 \mathrm{~min} /$ week vs. $>150 \mathrm{~min} /$ week) were analyzed. In the correlation analysis, only a weak correlation was found between post-pandemic physical activity duration (no exercise vs. $<150 \mathrm{~min} /$ week vs. $>150 \mathrm{~min}$ ) and happiness (coefficient $=0.205$ ). In other words, as the duration of physical activity increased, the happiness scores also increased.

When the happiness ratings between the participants who did physical activity $(<150 \mathrm{~min} /$ week $+>150 \mathrm{~min} /$ 
Table 2. Evaluation of physical activity habits in terms of physical activity time before the pandemic

\begin{tabular}{lccr}
\hline Physical activity during home stay & \multicolumn{3}{c}{$\begin{array}{c}\text { Physical activity per } \\
\text { week before the pandemic }\end{array}$} \\
\cline { 2 - 4 } & Non-exerciser & $<\mathbf{1 5 0}$ min/week & $>150$ min/week \\
\hline Non-exerciser & $91(65.5)$ & $21(35.0)$ & $42(37.8)$ \\
$<150 \mathrm{~min} /$ week & $39(28.1)$ & $27(45.0)$ & $42(37.8)$ \\
$>150 \mathrm{~min} /$ week & $9(6.5)$ & $12(20.0)$ & $27(24.3)$ \\
\hline
\end{tabular}

Descriptive statistics were given as number (\%). ${ }^{*}$ Marginal homogeneity test.

Table 3. Evaluation of physical activity habits in terms of regular physical activity before the pandemic (time independent)

\begin{tabular}{cccc}
\hline $\begin{array}{l}\text { Physical activity } \\
\text { during home stay }\end{array}$ & \multicolumn{3}{c}{$\begin{array}{c}\text { Engaged in regular } \\
\text { physical activity before } \\
\text { the pandemic (time } \\
\text { independent) }\end{array}$} \\
\cline { 2 - 4 } & Yes & No & P \\
\hline Yes & $108(63.1)$ & $48(34.5)$ & 0.024 \\
No & $63(36.8)$ & $91(65.5)$ & \\
\hline
\end{tabular}

Descriptive statistics were given as number (\%). *McNemar test.

week) and did not engage in regular physical activity after the pandemic were compared, the happiness scores of those who did physical activity were significantly higher $(p=0.002)$. When the happiness ratings of the participants were examined according to the duration of physical activity, a statistically significant difference was found between the groups in post-pandemic setting ( $p=0.007)$. Happiness score was found lower in non-exercisers group. These findings are summarized in Table 5.

\section{Discussion}

The results of our study demonstrated that pandemic has changed people's, in our study healthcare worker, physical activity habits. Some of the people who do physical activity for more than $150 \mathrm{~min} /$ week tend to do less or quitted regular physical activity completely. Some of the people who did not engage in regular physical activity before the pandemic started to do physical activity during lockdown. However, physical activity time has decreased due to pandemic, in other words due to restrictions as expected. Walking time $>10 \mathrm{~min}$ is also included in our study as aerobic exercise/physical activity. Therefore, it can be concluded that our results are consistent with a previous descriptive study using smartphones to track daily step counts. Tison et al. ${ }^{[16]}$ reported a rapid worldwide decrease up to $48.7 \%$ in step counts, especially in regions with lockdowns. Górnicka et al. ${ }^{[17]}$ also reported a reduction over $40 \%$ in physical activity as a result of their similar designed electronic survey with 2381 respondents during quarantine in Poland. In our study, 33.9\% (105/310) of the participants reported reduced physical activity. The reduction of exercise time might be explained through the inability to turn home to a gym for various reasons ${ }^{[18]}$ and through anxiety levels, but in healthcare workers' case, increased physical and emotional stress cannot be ignored.

Although we accept $150 \mathrm{~min} /$ week as the threshold value for the purpose of separating physically active and inactive individuals in further analyzes in our study, this value is also controversial in the literature. ${ }^{[19]}$ Although this threshold value is based on studies related to the prevention of various diseases and mortality, ${ }^{[20,21]}$ there is no optimal agreed aerobic exercise/physical activity time threshold value in the literature that has been shown to have an effect on musculoskeletal pain intensity and happiness and anxiety levels that we investigated in our study. However, given that painful individuals may have less exercise toler-

Table 4. Evaluation of physical activity in terms of physical activity time before the pandemic

\begin{tabular}{lccc}
\hline $\begin{array}{l}\text { Physical activity during } \\
\text { home stay }\end{array}$ & \multicolumn{2}{c}{$\begin{array}{c}\text { Physical activity time per } \\
\text { week before the pandemic }\end{array}$} & P \\
\cline { 2 - 3 } & $<\mathbf{1 5 0} \mathbf{~ m i n / w e e k}$ & $>\mathbf{1 5 0}$ min week & \\
\hline$<150 \mathrm{~min} /$ week & $178(89.4)$ & $84(75.7)$ & $<0.001$ \\
$>150 \mathrm{~min} /$ week & $21(10.6)$ & $27(24.3)$ & \\
\hline
\end{tabular}

Descriptive statistics were given as number (\%). ${ }^{*}$ McNemar test. 
Table 5. Evaluation of mood in terms of physical activity habits

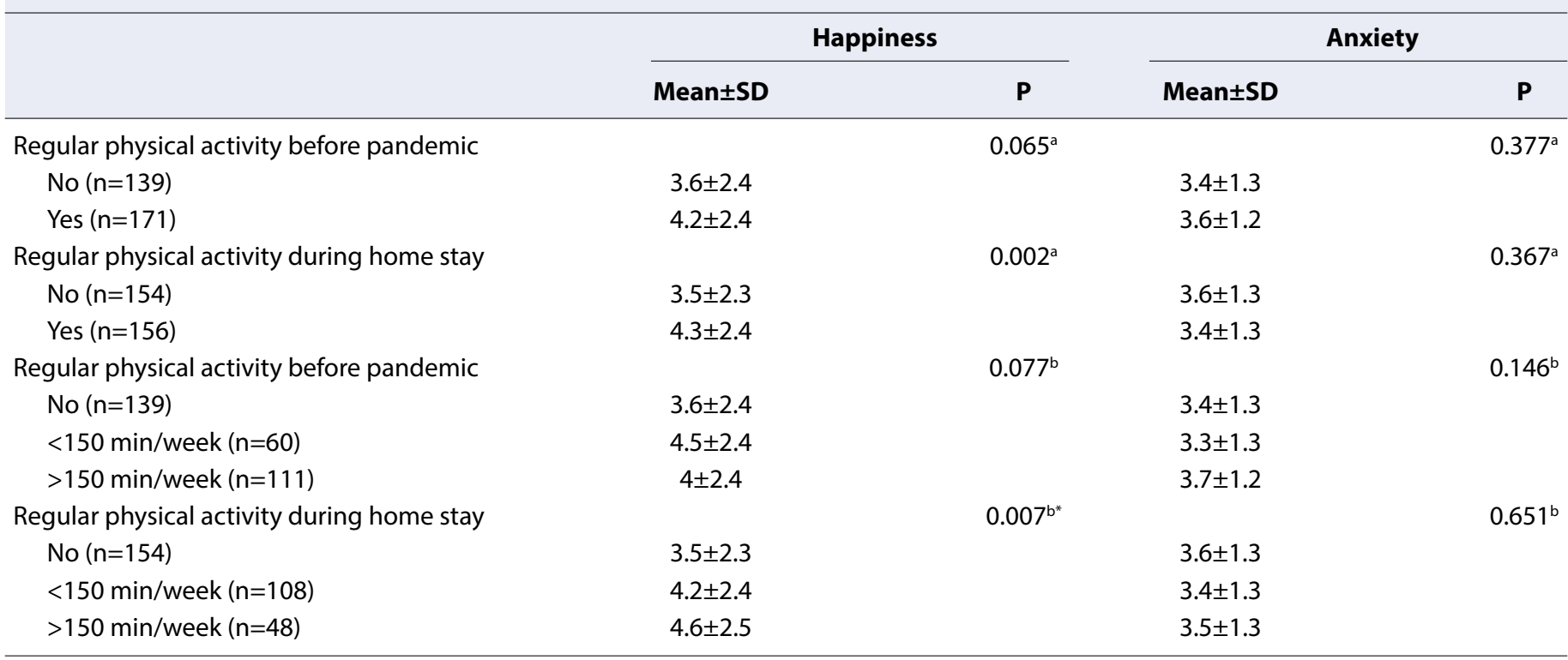

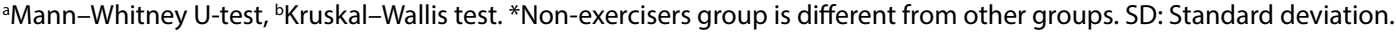

ance, the recommended $150 \mathrm{~min} /$ week threshold for general health benefits may be high. Aerobic physical activity intensity was also not questioned in detail, but we mainly focused on physical activity time which could be a limitation of our study.

Exercise has a very important role in musculoskeletal pain. Evidence showing the positive effects of regular exercise on pain is increasing, especially in patients with chronic pain. ${ }^{[22]}$ In a meta-analysis investigating the effectiveness of walking-based interventions in chronic musculoskeletal pain, it was demonstrated that aerobic exercise could improve pain. ${ }^{[23]}$ It is a limitation of our study that pain duration is not questioned in detail. However, similar to ours, in a Korean study that grouped the participants as active and inactive individuals over the $150 \mathrm{~min} /$ week threshold, and, unlike our study, investigated the elderly female population, it was stated that the inactive group generally experienced more serious problems related to pain. ${ }^{[2]}$ In our study, there was no difference in musculoskeletal pain between individuals who do physical activity regularly and those who do not, even in further analysis with $150 \mathrm{~min} /$ week threshold.

However, in studies investigating the relationship between psychosocial status and pain, it has been reported that psychosocial problems have a negative effect on parameters related to pain. ${ }^{[25-31]}$ Similarly, it is known that social isolation, as a natural consequence of restrictions, has a negative effect on pain and physical activity level too. ${ }^{[32-35]}$ In a study conducted in our country at the same time as our study, in which healthcare workers, mostly nurses, were evaluated, it was found that approximately one-third of the participants experienced severe extremely severe depression and anxiety, and a quarter of them were under severe extremely severe stress. ${ }^{[36]}$ In a study conducted in Spain, in which individuals with chronic pain $(52.2 \%$ musculoskeletal pain) were included, most of the participants stated that their pain increased, ${ }^{[37]}$ as in our study. Although no significant relationship with physical activity status was found in our study, people tend to suffer more from the musculoskeletal pain. Evaluating the data together, the psychosocial state and workload of health-care professionals during the pandemic can be associated with the increase in pain. Furthermore, failure to determine a relationship between physical activity status and pain may be due to these psychosocial factors. Another limitation of our study is that we used a numeric scale instead of common generic scales for the evaluation of depression and anxiety, and this may have reduced inference efficiency.

While there was no relationship between physical activity status before the pandemic and happiness, doing physical activity during home stay was associated with higher happiness ratings and did not depend on physical activity duration. However, there is no relationship between anxiety and physical activity before and after the pandemic. In general, considering the mean values, it was observed that the participants were mostly unhappy and very anxious as in the study of Alan et al. ${ }^{[36]}$ In a survey study investigating the effects of the pandemic on the mental health of medical students and newly qualified doctors in the UK, the mood of those who exercise to maintain their mental 
well-being was better similar to our study. ${ }^{[38]}$ As a result of a large-scale study investigating the exercise parameters to prevent depression, it was stated that the protective effect occurs at low level of physical activity (60 min/week) and is independent of intensity ${ }^{[39]}$ This result is consistent with our findings that the participants in our study who do physical activity regularly, regardless of the physical activity duration threshold $150 \mathrm{~min} /$ week, were less unhappy.

The main limitations of the present study are the absence of the details related to physical activity intensity and pain duration. The non-use of generic scales for depression and anxiety and also for physical activity, as well as the exercise duration threshold value "150 min/week," might affect the results. Another limitation of our study is that the physical activity performed in the hospital was not included in the total weekly duration, and therefore, for some participants, the survey may have shown the weekly physical activity time shorter than it actually was.

\section{Conclusion}

Pandemic caused a decrease in physical activity, an unhappy and anxious mood, and an increase in musculoskeletal pain of healthcare workers. Regular exercisers were less unhappy, but no relationship between physical activity and musculoskeletal pain was found which might be related to psychosocial state of the participants.

\section{Disclosures}

Ethics Committee Approval: The study was approved by the Local Ethics Committee of University of Health Sciences, Sisli Hamidiye Etfal Teaching and Research Hospital (June 30, 2020/2861).

Peer-review: Externally peer-reviewed.

Conflict of Interest: None declared.

Authorship Contributions: Concept - E.E.I., B.K., H.M.O.; Design - E.E.I., B.K.; Supervision - B.K.; Materials - E.E.I., S.D.; Data collection \&/or processing - E.E.I, S.D.; Analysis and/or interpretation E.E.I., A.S.; Literature search - E.E.I, A.S., S.D.; Writing - E.E.I., A.S.; Critical review - B.K., H.M.O.

\section{References}

1. Turkish Language Association Online Dictionary. Available at: https://sozluk.gov.tr/. Accessed Jan 10, 2021.

2. France-Presse A. Global virus deaths top 150,000 as US braces for lockdown protests. Available at: https://news.yahoo.com/ amphtml/global-virus-deaths-pass-150-000-trump-endorses-074827169.html?_twitter_impression=true. Accessed Dec 8, 2020.

3. World Health Organization. Physical activity. Available at: https:// www.who.int/news-room/fact-sheets/detail/physical-activity. Accessed Dec 8, 2020.

4. Harber MP, Kaminsky LA, Arena R, Blair SN, Franklin BA, Myers J, et al. Impact of cardiorespiratory fitness on all-cause and diseasespecific mortality: advances since 2009. Prog Cardiovasc Dis 2017;60:11-20. [CrossRef]

5. Howe TE, Shea B, Dawson LJ, Downie F, Murray A, Ross C, et al. Exercise for preventing and treating osteoporosis in postmenopausal women. Cochrane Database Syst Rev 2011:CD000333.

6. Huai P, Xun H, Reilly KH, Wang Y, Ma W, Xi B. Physical activity and risk of hypertension: a meta-analysis of prospective cohort studies. Hypertension 2013;62:1021-6. [CrossRef]

7. Lök S, Lök N. Efficiency of Physical Exercise Programs on Chronic Psychiatric Patients: A Systematic Review. Psikiyatride Guncel Yaklasimlar 2016;8:354. [CrossRef]

8. Mammen G, Faulkner G. Physical activity and the prevention of depression: a systematic review of prospective studies. Am J Prev Med 2013;45:649-57. [CrossRef]

9. Nauman J, Tauschek LC, Kaminsky LA, Nes BM, Wisløff U. Global fitness levels: findings from a web-based surveillance report. Prog Cardiovasc Dis 2017;60:78-88. [CrossRef]

10. Sui X, Sarzynski MA, Lee DC, Kokkinos PF. Impact of changes in cardiorespiratory fitness on hypertension, dyslipidemia and survival: an overview of the epidemiological evidence. Prog Cardiovasc Dis 2017;60:56-66. [CrossRef]

11. Wipfli BM, Rethorst CD, Landers DM. The anxiolytic effects of exercise: a meta-analysis of randomized trials and dose-response analysis. J Sport Exerc Psychol 2008;30:392-10. [CrossRef]

12. Wong CM, Lai HK, Ou CQ, Ho SY, Chan KP, Thach TQ, et al. Is exercise protective against influenza-associated mortality? PLoS One 2008;3:e2108. [CrossRef]

13. Dixit S. Can moderate intensity aerobic exercise be an effective and valuable therapy in preventing and controlling the pandemic of COVID-19? Med Hypotheses 2020;143:109854. [CrossRef]

14. Fernández-Lázaro D, González-Bernal JJ, Sánchez-Serrano N, Navascués LJ, Ascaso-Del-Río A, Mielgo-Ayuso J. Physical exercise as a multimodal tool for COVID-19: Could it be used as a preventive strategy? Int J Environ Res Public Health 2020;17:8496. [CrossRef]

15. Shepard RJ, Shek PN. Impact of physical activity and sport on the immune system. Rev Environ Health 1996;11:133-47. [CrossRef]

16. Tison GH, Avram R, Kuhar P, Abreau S, Marcus GM, Pletcher MJ, et al. Worldwide effect of COVID-19 on physical activity: a descriptive study. Ann Intern Med 2020;173:767-70. [CrossRef]

17. Górnicka M, Drywień ME, Zielinska MA, Hamułka J. Dietary and lifestyle changes during COVID-19 and the subsequent lockdowns among Polish adults: a cross-sectional online survey PLifeCOVID-19 study. Nutrients 2020;12:2324. [CrossRef]

18. De Oliveira Neto L, Elsangedy HM, Tavares VD, Teixeira C, Behm D, Da Silva-Grigoletto ME. \#Traininginhome - Home-based training during COVID-19 (SARS-COV2) pandemic: physical exercise and behavior-based approach. Brazilian Journal of Exercies Physiology 2020;19:1-11. [CrossRef]

19. Warburton DE, Bredin SS. Reflections on Physical activity and health: what should we recommend? Can J Cardiol 2016;32:495-504. 
20. Wang Y, Nie J, Ferrari G, Rey-Lopez JP, Rezende LFM. Association of physical activity intensity with mortality: a national cohort study of 403681 US dults. JAMA Intern Med 2021;181:203-11.

21. Warburton DE, Charlesworth S, Ivey A, Nettlefold L, Bredin SS. A systematic review of the evidence for Canada's Physical Activity Guidelines for Adults. Int J Behav Nutr Phys Act 2010;7:39. [CrossRef]

22. Rice D, Nijs J, Kosek E, Wideman T, Hasenbring MI, Koltyn K, et al. Exercise-induced hypoalgesia in pain-free and chronic pain populations: state of the art and future directions. J Pain 2019;20:1249-66. [CrossRef]

23. O'Connor SR, Tully MA, Ryan B, Bleakley CM, Baxter GD, Bradley $\mathrm{JM}$, et al. Walking exercise for chronic musculoskeletal pain: systematic review and meta-analysis. Arch Phys Med Rehabil 2015;96:724-34. [CrossRef]

24. Lim HS, Yoo JJ. Association between health indicators and healthrelated quality of life according to physical activity of older women. Healthcare (Basel) 2020;8:507. [CrossRef]

25. Gatchel RJ, Polatin PB, Mayer TG. The dominant role of psychosocial risk factors in the development of chronic low back pain disability. Spine (Phila Pa 1976) 1995;20:2702-9. [CrossRef]

26. Kehlet $\mathrm{H}$, Jensen TS, Woolf CJ. Persistent postsurgical pain: risk factors and prevention. Lancet 2006;367:1618-25. [CrossRef]

27. Linton SJ, Shaw WS. Impact of psychological factors in the experience of pain. Phys Ther 2011;91:700-11. [CrossRef]

28. Merlijn VP, Hunfeld JA, van der Wouden JC, Hazebroek-Kampschreur AA, Koes BW, Passchier J. Psychosocial factors associated with chronic pain in adolescents. Pain 2003;101:33-43. [CrossRef]

29. Tang J, Gibson SJ. A psychophysical evaluation of the relationship between trait anxiety, pain perception, and induced state anxiety. J Pain 2005;6:612-9. [CrossRef]

30. van Wijk G, Veldhuijzen DS. Perspective on diffuse noxious inhibitory controls as a model of endogenous pain modulation in clini- cal pain syndromes. J Pain 2010;11:408-19. [CrossRef]

31. Weissman-Fogel I, Sprecher E, Pud D. Effects of catastrophizing on pain perception and pain modulation. Exp Brain Res 2008;186:79-85. [CrossRef]

32. Jaremka LM, Andridge RR, Fagundes CP, Alfano CM, Povoski SP, Lipari AM, et al. Pain, depression, and fatigue: Ioneliness as a longitudinal risk factor. Health Psychol 2014;33:948-57. [CrossRef]

33. Shankar A, McMunn A, Banks J, Steptoe A. Loneliness, social isolation, and behavioral and biological health indicators in older adults. Health Psychol 2011;30:377-85. [CrossRef]

34. Smith T. "On their own": social isolation, loneliness and chronic musculoskeletal pain in older adults. Quality in Ageing and Older Adults 2017;18:87-92. [CrossRef]

35. Smith TO, Dainty JR, Williamson E, Martin KR. Association between musculoskeletal pain with social isolation and loneliness: analysis of the English Longitudinal Study of Ageing. Br J Pain 2019;13:82-90. [CrossRef]

36. Alan H, Eskin Bacaksiz F, Tiryaki Sen H, Taskiran Eskici G, Gumus E, Harmanci Seren AK. "I'm a hero, but horizontal ellipsis ": an evaluation of depression, anxiety, and stress levels of frontline healthcare professionals during COVID-19 pandemic in Turkey. Perspect Psychiatr Care 2021;57:1126-36. [CrossRef]

37. Nieto R, Pardo R, Sora B, Feliu-Soler A, Luciano JV. Impact of COVID-19 lockdown measures on Spanish people with chronic pain: an online study survey. J Clin Med 2020;9:3558. [CrossRef]

38. Coyle C, Ghazi H, Georgiou I. The mental health and well-being benefits of exercise during the COVID-19 pandemic: a cross-sectional study of medical students and newly qualified doctors in the UK. Ir J Med Sci 2021;190:925-6. [CrossRef]

39. Harvey SB, Øverland S, Hatch SL, Wessely S, Mykletun A, Hotopf $M$. Exercise and the prevention of depression: Results of the HUNT cohort study. Am J Psychiatry 2018;175:28-36. [CrossRef] 